\title{
Reaction Mechanism of the Aluminum Nanoparticle: Physicochemical Reaction and Heat/Mass Transfer
}

\author{
Qingzhao Chu, Baolu Shi,* Lijuan Liao,* Xiangrui Zou, Kai H Luo, and Ningfei Wang \\ Cite This: J. Phys. Chem. C 2020, 124, 3886-3894 \\ Read Online
}

ABSTRACT: A lack of clarity in the reaction mechanism of the aluminum nanoparticle (ANP) severely restricts its effective applications. By describing the physicochemical evolution of ANP burning in typical oxidizers $\left(\mathrm{CO}_{2}, \mathrm{H}_{2} \mathrm{O}\right.$, and $\left.\mathrm{O}_{2}\right)$ at the nanoscale, three principal reaction modes including physical adsorption, chemical adsorption, and reactive diffusion were captured during the reaction. Initially, oxidizer molecules are physically and chemically adsorbed on the ANP surface until ignition in which reaction heat plays a more important role in contrast to heat transfer. Subsequently, partial oxidizer atoms adsorbed by surface diffuse across the shell to react with the $\mathrm{Al}$

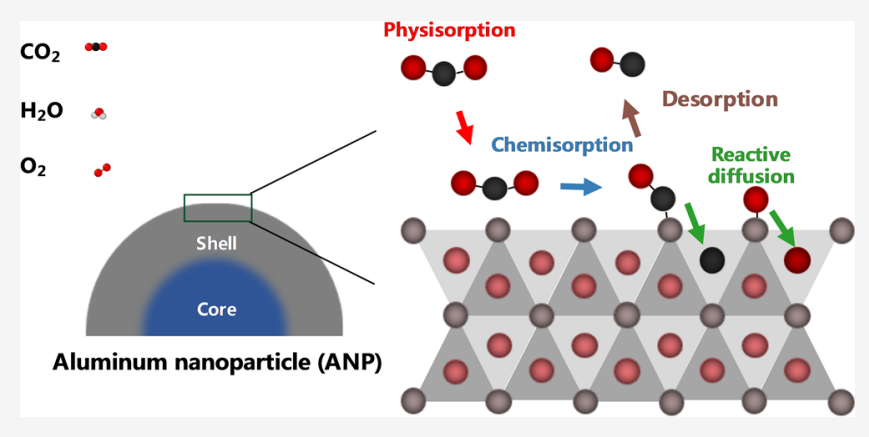
core, presenting the dominant mode of reactive diffusion. It is assumed that the binding energy between $\mathrm{Al}$ and oxidizer atoms is in an inverse relation to atomic diffusivity but is positively correlated to reaction heat, resulting in various ANP structures and heat release rates. Our findings provide design guidelines to control various oxidizer supplies with respect to the reaction stages to balance the energy release and the residence time of ANP.

\section{INTRODUCTION}

Aluminum particles, due to their high specific energy density $(31 \mathrm{~kJ} / \mathrm{g})$ and abundance on Earth, have been widely used as energetic materials in many combustion and explosive systems, ${ }^{1}$ such as space propulsion, ${ }^{2}$ underwater propulsion, ${ }^{3}$ and even internal-combustion engines. ${ }^{4,5}$ To meet challenges in $\mathrm{Al}$ particle burning such as ignition difficulty and incomplete combustion, ${ }^{6}$ the aluminum nanoparticle (ANP) has been proposed as an alternative to its microsized counterpart. With a higher surface-to-volume ratio and shorter diffusion distance, ANP has excellent physicochemical properties, such as low ignition temperature and high reaction rate. ${ }^{7}$

With an intense reaction at the minimal temporal-spatial scale, the detailed reaction process of ANP is hard to be captured efficiently in measurements, resulting in the difficulty in controlling the ANP ignition, reaction, and furthermore effective energy release. The oxidizer property in the atmosphere is one of the significant factors to the reaction process of ANP. In oxygen circumstances, ANP combustion has been widely investigated due to $\mathrm{O}_{2}$ richness in air. ${ }^{8-11}$ However, an oxygen-deprived occasion is typical in practical applications. Taking the solid rocket engine as an example, ANP reacts with propellant products mainly consisting of carbon dioxide $\left(\mathrm{CO}_{2}\right)$ and steam $\left(\mathrm{H}_{2} \mathrm{O}\right)$ rather than $\mathrm{O}_{2}$. Another case is the Mars space exploration mission in which $\mathrm{CO}_{2}$ is the principal constituent of the planet's atmosphere. The ANP reaction with $\mathrm{CO}_{2}$ provides the major energy for propulsion. ${ }^{12}$ Besides, in underwater propulsion, $\mathrm{H}_{2} \mathrm{O}$ is the primary oxidizer. As a consequence, the clarification of ANP reaction mechanisms taking the oxidizers into account is of great significance.

Over the past decades, considerable efforts have been made to study the reaction mechanism of ANP, which is strongly affected by particle size, ${ }^{13}$ oxidizer properties, ${ }^{14}$ and environmental temperature and pressure. ${ }^{15,16}$ Sundaram et al. ${ }^{17}$ summarized three possible burning scenarios for ANP. They pointed out that the mass diffusion across the oxide layer of the particle and polymorphic phase transformation induce the ignition, and the reaction may occur at the core-shell interface or the outer surface of ANP depending on diffusion coefficients of aluminum and oxidizer atoms. Meanwhile, Levitas and Samani ${ }^{13}$ proposed a melt-dispersion mechanism in which fast ignition results from the dispersion of small $\mathrm{Al}$ clusters in the oxidizer. These findings have shed some light on the complexity, but the understanding is far from being complete. Until now, no scientific consensus on the reaction mechanism of ANP has yet been reached. To effectively capture the physicochemical evolution of the microstructure is still a big challenge.

Recently, reactive molecular dynamics (RMD) calculations have been employed to examine the oxidation of ANP, ${ }^{18-22}$ which are proven to be more powerful and accurate than most

Received: December 10, 2019

Revised: January 19, 2020

Published: January 19, 2020 

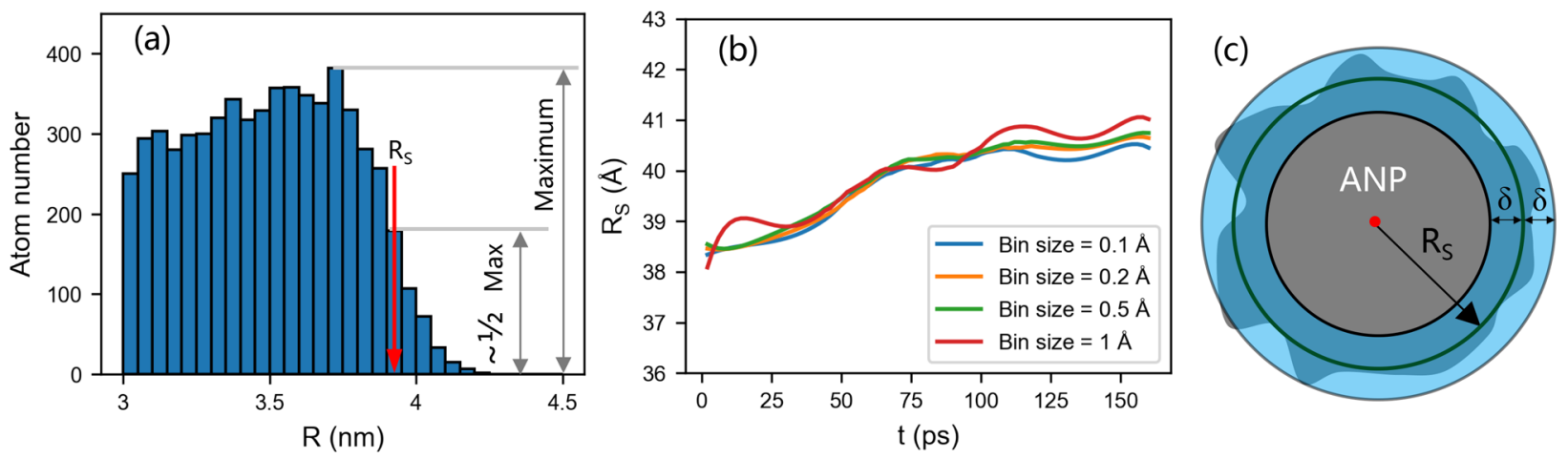

Figure 1. Number of $\mathrm{Al}$ atoms in each shell toward the outer surface (a), temporal variation of $R_{\mathrm{s}}$ with respect to bin size (b), and sketch of the ANP surface region $(c)$.
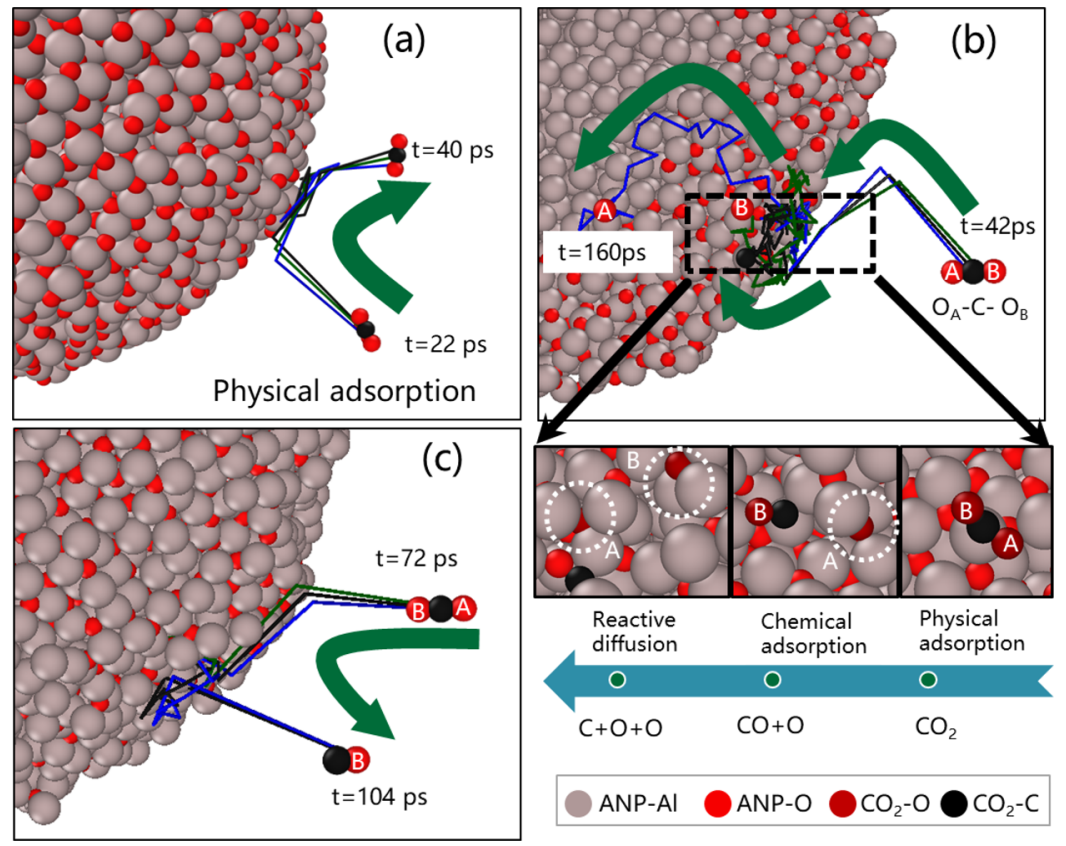

Figure 2. Trajectories of collision between ANP and $\mathrm{CO}_{2}$ molecules: (a) physical adsorption and desorption of $\mathrm{CO}_{2}$, (b) physical/chemical adsorption and reactive diffusion, and (c) physical/chemical adsorption of $\mathrm{CO}_{2}$ and desorption of $\mathrm{CO}$.

semiempirical methods. ${ }^{23,24}$ However, most of the previous works focus on combustion characteristics of ANP with $\mathrm{O}_{2}$ after ignition. In our previous work on the room-temperature ANP burning in the high-temperature $\mathrm{O}_{2}$ atmosphere, ${ }^{25}$ four stages of preheating, melting, fast $\mathrm{Al}$ core oxidation, and shell oxidation were defined to depict the detailed reacting process. Particular attention has been paid to the temporal variations of the particle itself, such as density, temperature, and atomic diffusion to detail its evolution. However, several key questions remain unanswered, including the physical and chemical interactions between ANP and oxidizer molecules during the reaction, the governing reaction mode in each stage, and the corresponding heat transfer and reaction heat release characteristics. Such information may significantly advance the development of ANP-based power systems by improving ignition quality, shortening the reaction time, prompting complete ANP burning, and adjusting the heat release rate.

This study aims to obtain an insightful understanding of reaction and heat/mass transfer mechanisms of core-shell ANP burning in typical oxidants such as $\mathrm{CO}_{2}, \mathrm{H}_{2} \mathrm{O}$, and $\mathrm{O}_{2}$. Attention is focused on the collision of the oxidizer with the
ANP surface and subsequent diffusion. Burning in a hot oxidizer atmosphere, the evolution of the ANP microstructure, heat transfer, and reaction heat release in each stage during the reaction were examined. Subsequently, the governing parameters related to the oxidizer type on the reaction modes, microstructure evolution, and heat transfer as well as reaction heat release were clarified. Obtained controlling parameters and their effects on the reaction proposed in this paper provide a useful path to improve the efficiency of ANP burning.

\section{METHOD}

The reactions of ANP in oxidizers were described by the reactive force field (ReaxFF) at the nanoscale. The detailed modeling and MD runs can be referred to our previous work. ${ }^{25}$ RMD simulations and visualizations were conducted in the LAMMPS package ${ }^{26}$ and OVITO, ${ }^{27}$ respectively. Some points of modeling and MD runs are described here briefly. An ANP with $2 \mathrm{~nm}$ radius for the core and $2 \mathrm{~nm}$ thickness for the amorphous alumina shell ${ }^{28}$ was established in advance. 2700 oxidizer molecules at $2000 \mathrm{~K}$ were modeled to accelerate the reaction in calculations. A $16 \mathrm{~nm} \times 16 \mathrm{~nm} \times 16 \mathrm{~nm}$ box with 
periodic boundary conditions filling with a given type of oxidizer molecule and a single ANP was also prepared. Three samples in one case were provided to meet the statistical requirements. Typical oxidizers $\mathrm{CO}_{2}, \mathrm{H}_{2} \mathrm{O}$, and $\mathrm{O}_{2}$ were selected here. Each mixture was simulated in the NVE ensemble for 160 ps with a time step of 0.2 fs.

As a key element, the ANP surface should be defined quantitatively. Taking an example in one run, the outmost $\mathrm{Al}$ atom locates at $R=4.25 \mathrm{~nm}$ (particle radius, predesigned as 4 $\mathrm{nm}$ ) because of the convex surface at the end of relaxation. Obviously, this edge is improper to indicate the surface of a particle. In this study, one ANP was divided into shells as small bins. The distributions of $\mathrm{Al}$ atoms along the particle radius are plotted in Figure 1 as an illustration. The radius of the ANP surface $\left(R_{\mathrm{s}}\right)$ is defined as the radius of a shell where the $\mathrm{Al}$ atom number is approximately half of the maximum value across it (Figure 1a). As comparatively analyzed in Figure 1b, a bin size of $0.5 \AA$ is enough to describe $R_{\mathrm{s}}$ accurately. Accordingly, the surface region is represented by the shell within $R_{s} \pm \delta$ (light blue region lying between two dashed spheres in Figure 1c). A value of $\delta=1.8 \AA$, which is in the range of the chemical bond length of $\mathrm{Al}-\mathrm{C} / \mathrm{Al}-\mathrm{H} / \mathrm{Al}-\mathrm{O}$, is sufficient to obtain reasonable results in three kinds of oxidizers. The sensitivities of $\delta$ have been examined in terms of the temporal variations of the surface atom number density in the Supporting Information (Figure S1).

\section{RESULTS}

3.1. Reaction Mode. Choosing as a reference, the characteristics of the ANP reaction in $\mathrm{CO}_{2}$, including collision details tracked by atom trajectories, evolution of the ANP microstructure, temporal variation of oxidizer and adsorbed atoms, and the contribution of heat transfer and reaction, were first described.

The initial reaction of ANP is the oxidizer molecule adsorption on the ANP surface via collisions. After first collision, three typical trajectories were captured as illustrated in Figure 2.

In Figure $2 \mathrm{a}$, a $\mathrm{CO}_{2}$ molecule is attracted by the ANP and absorbed on the surface for a short while followed by desorption. Without bond breaking or formation, the physical adsorption dominates in this stage. In Figure $2 b$, the initiation absorption on the surface of the $\mathrm{CO}_{2}$ molecule is similar to that shown in Figure 2a. Unlike repelling, the breaking of a C$\mathrm{O}$ bond $\left(\mathrm{C}-\mathrm{O}_{\mathrm{A}}\right)$ occurs following the surface absorption as enlarged at the lower-right corner. One $\mathrm{O}$ atom $\left(\mathrm{O}_{\mathrm{A}}\right)$ diffuses into the inner of the nanoparticle, and the left $\mathrm{CO}\left(\mathrm{CO}_{\mathrm{B}}\right)$ molecule is still on the surface, indicating the chemical adsorption. As the reaction proceeds, another $\mathrm{C}-\mathrm{O}$ bond $(\mathrm{C}-$ $\mathrm{O}_{\mathrm{B}}$ ) breaks and $\mathrm{O}_{\mathrm{B}}$ also diffuses inward. Tracking the motion as displayed by the blue trajectory, one adsorbed atom $\left(\mathrm{O}_{\mathrm{A}}\right)$ diffuses continually inside even across the shell, which is defined as the reactive diffusion. ${ }^{29-33}$ Furthermore, rather than continued breaking of the $\mathrm{C}-\mathrm{O}$ bond, there is also the surface repelled $\mathrm{CO}$ molecule as illustrated in Figure 2c. The phenomena of a $\mathrm{CO}_{2}$ molecule presenting different adsorption modes will be explained in Section 3.2.

Accordingly, physisorption, chemisorption, and reactive diffusion are three principal modes captured in ANP-oxidizer interaction. Generally, adsorption energy and bond length are used to differentiate physisorption from chemisorption for a unimolecular adsorption reaction in density functional theory (DFT) calculations. ${ }^{34-36}$ For simplicity, bond length is adopted here to differentiate the adsorption mode. During the reactive diffusion state, the oxidizer atoms diffuse inside across the shell, yielding their radial positions smaller than $\left(R_{\mathrm{s}}\right.$ $-\delta$ ), which is considered as the criteria to count the number of inner diffused oxidizer atoms.

The stable bond lengths for physical adsorption $\left(L_{\text {phy }}\right)$ were calculated with the help of an $\alpha-\mathrm{Al}_{2} \mathrm{O}_{3}$ (001) slab as an analogue nanoparticle surface. The stable bond length between the $\mathrm{Al}$ atom from $\mathrm{Al}_{2} \mathrm{O}_{3}$ and the $\mathrm{C}$ atom from $\mathrm{CO}_{2}$ is $2.03 \AA$. As an oxidizer molecule breaks its intramolecular bond and forms a new bond with the ANP surface, the bond length becomes shorter than $L_{\text {phy }}$, indicating the mode evolving from physisorption to chemisorption.

The reaction modes indicated by absorbed and diffused oxidizer molecules/atoms during the four stages of ANP combustion $^{25}$ were counted and are plotted in Figure 3a,

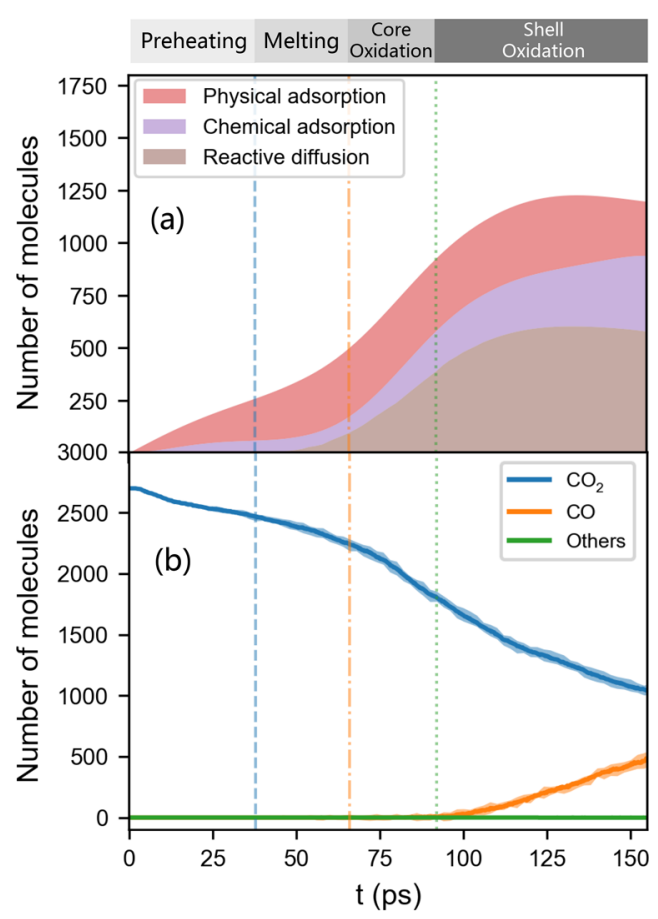

Figure 3. Number evolutions in four stages during the reaction: (a) numbers of oxidizer molecules indicating physical, chemical adsorption, and reactive diffusion and (b) molecule/atom numbers in the ambient condition.

accompanied with temporal evolutions of ambient species shown in Figure 3b. As indicated in Figure 3a, physical adsorption dominates in both preheating and melting stages with a continuous increase. On the contrary, chemical adsorption accounts for very low proportions in the initial two stages with a subtle rise. Reactive diffusion occurs at the late period of melting. After ignition, chemisorption and reactive diffusion enhance sharply.

In Figure 3b, solid curves and corresponding light-color areas are the average values of three runs and the error bands, respectively. $\mathrm{CO}_{2}$ molecules are consumed continuously with an increasing consuming rate after ignition (across the orange dashed-dot line in Figure 3). CO molecules appear in the ambient condition in the last stage. Gradually, the CO production rate (slope of the $\mathrm{CO}$ number evolution) approaches the consumption rate of ambient $\mathrm{CO}_{2}$ molecules. 


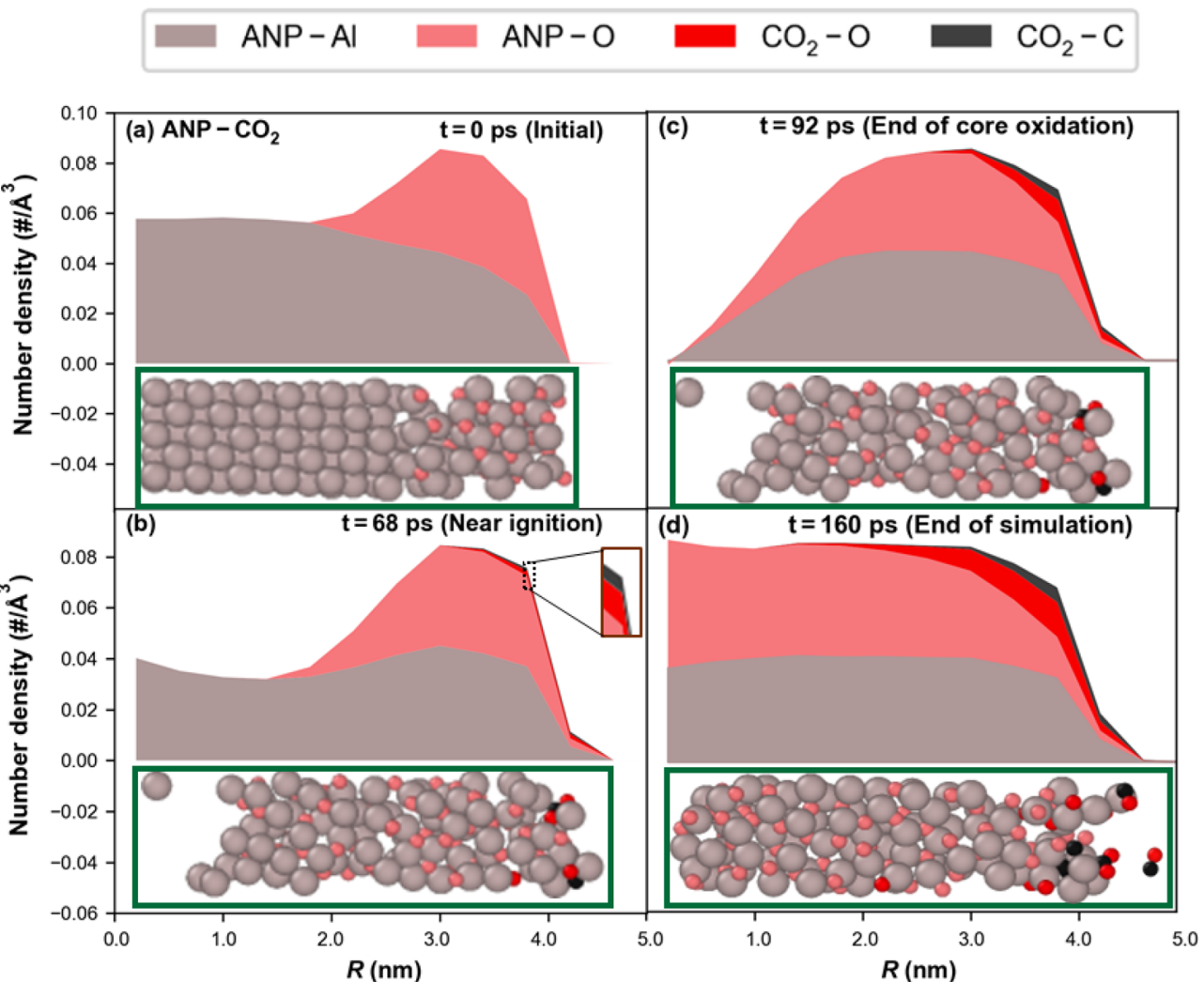

(e) $t=160 \mathrm{ps}$

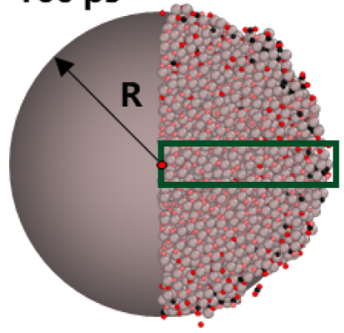

(f1) Surface without $C$ $E_{\text {ad }}=-34.73 \mathrm{kcal} / \mathrm{mol}$

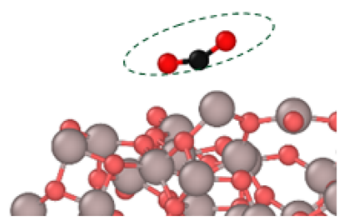

(f2) Surface with C $E_{\text {ad }}=-23.40 \mathrm{kcal} / \mathrm{mol}$

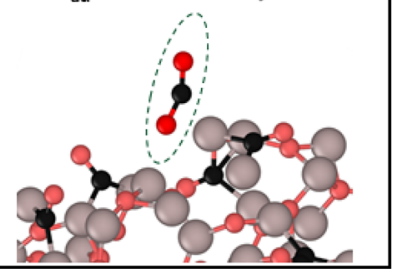

Figure 4. Radial number density distribution (top) and slice snapshot (bottom) of ANP at the initial state (a), near ignition (b), core runout (c), and simulation end (d), illustration of $\mathrm{C}$ atom distribution (e), and adsorption energy of the $\mathrm{CO}_{2}$ molecule on a surface at two statuses (f).

Owing to ultralow adsorption energy, ${ }^{37}$ the reaction between $\mathrm{CO}$ and ANP can be neglected.

3.2. Microstructure Evolution. The ANP microstructure varies as the reaction proceeds, and its evolution is depicted by the radial distributions of each type of atom number density in Figure $4 \mathrm{a}-\mathrm{d}$. As the density of the core decreases due to the melting, $\mathrm{O}$ atoms in the oxide shell gradually diffuse into the core. Before ignition, most adsorbed oxidizer atoms locate on the nanoparticle surface as shown in Figure $4 \mathrm{~b}$. After ignition, both inward diffusion of shell $\mathrm{O}$ atoms and adsorbed oxidizer atoms accelerate, resulting in inward expanding area for both number densities as illustrated in Figure 4c. The distributions of $\mathrm{Al}$ and $\mathrm{O}$ atoms approach to be uniform gradually at the end of simulation in Figure 4d. Meanwhile, the number density of adsorbed $\mathrm{C}$ atoms shows a slight rise near the nanoparticle surface. Even though, as the snapshot diagrammed in Figure 4e illustrated, there are plenty of $\mathrm{C}$ atoms featuring reactive diffusion in the nanoparticle, corresponding to the reaction mode in Figure 3a.

Returning back to the appearance of $\mathrm{CO}$ and the plateau of the adsorbed molecules in the shell oxidation stage as described in Figure 3, the effect of the surface adhering $\mathrm{C}$ atom on the surface adsorption energy with a single $\mathrm{CO}_{2}$ molecule was examined, as illustrated in Figure 4f1,f2. A raw amorphous alumina surface (Figure 4f1) and a configuration extracted during an $\mathrm{RMD}$ running at $100 \mathrm{ps}$ (Figure $4 \mathrm{f} 2$ ) were prepared. The $\mathrm{C}$ atom adhering to the surface brings low adsorption energy, resulting in adsorption instability. As a result of $\mathrm{CO}_{2}$ dissociation, $\mathrm{CO}$ is repelled and another $\mathrm{O}$ atom is adhered to the surface.

The reaction mechanism of ANP in a $\mathrm{CO}_{2}$ atmosphere is summarized as illustrated in Figure 5. The reaction process

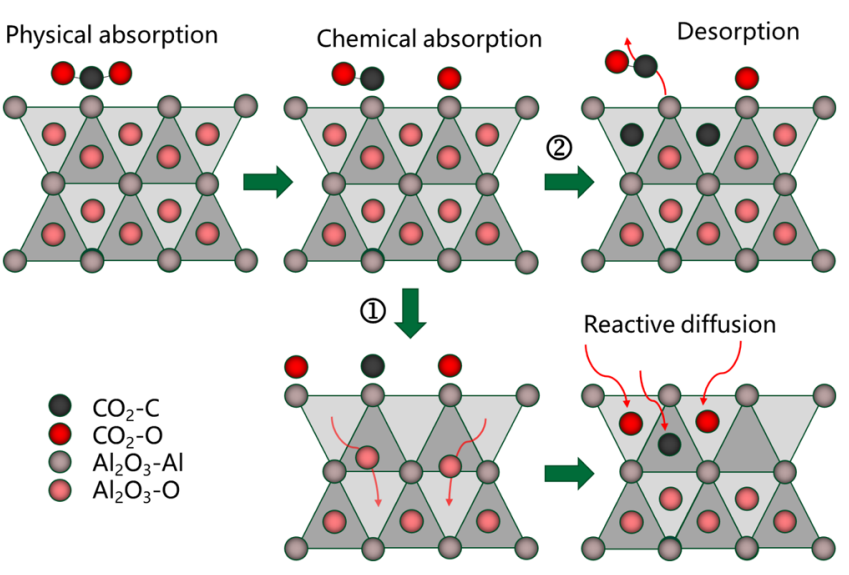

Figure 5. Schematic diagram of surface adsorption and reactive diffusion during the ANP reaction.

principally experiences physisorption, chemisorption, and reactive diffusion. The adsorbed oxidizer molecules and nanoparticle surface maintain the relative stability in the initial mode as physisorption. The reaction mode evolves to chemisorption when partial adsorbed oxidizer molecules break parts of chemical bonds. With the help of input energy, the $\mathrm{O}$ atoms in the oxide shell diffuse inward followed by the inward diffusion of surface adsorbed atoms (route 1). As the surface $\mathrm{C}$ atom concentration increases, the chemically adsorbed $\mathrm{CO}_{2}$ is favorable to be repelled from the surface in the form of the $\mathrm{CO}$ molecule instead of diffusing into the oxide shell (route 2).

3.3. Heat Transfer and Reaction Heat Release. Accompanying the ANP-oxidizer interaction, plenty of heat 
is transferred to ANP in the form of heat transfer and reaction heat release. It is of vital importance to ANP melting and ignition. Accordingly, the energy variations of heat transfer $\left(Q_{\text {trans }}\right)$ to ANP and reaction heat release $\left(Q_{\text {reac }}\right)$ were examined. The heat transfer induced by a temperature difference is quantified by the variation of oxidizer kinetic energy $\left(\Delta E_{\mathrm{ke}}\right)$. Meanwhile, the reaction heat release can be calculated by potential energy variation of the total system $\left(\Delta E_{\mathrm{pe}}\right)$ since the $\mathrm{CO}_{2}$ molecular does not decompose before the reaction. Their rates $\dot{Q}_{\text {trans }}$ and $\dot{Q}_{\text {reac }}$ are given by $\dot{Q}=\Delta \dot{E}$ / $\left(3 k_{\mathrm{B}} N_{\mathrm{p}}\right)$, where $\Delta \dot{E}$ is the energy variation rate, $k_{\mathrm{B}}$ is the Boltzmann constant, and $N_{\mathrm{p}}$ is the number of particle atoms.

Temporal variations of $\dot{Q}_{\text {trans }}$ and $\dot{Q}_{\text {reac }}$ are plotted in Figure 6. In Figure 6a, the solid curves and the corresponding light-
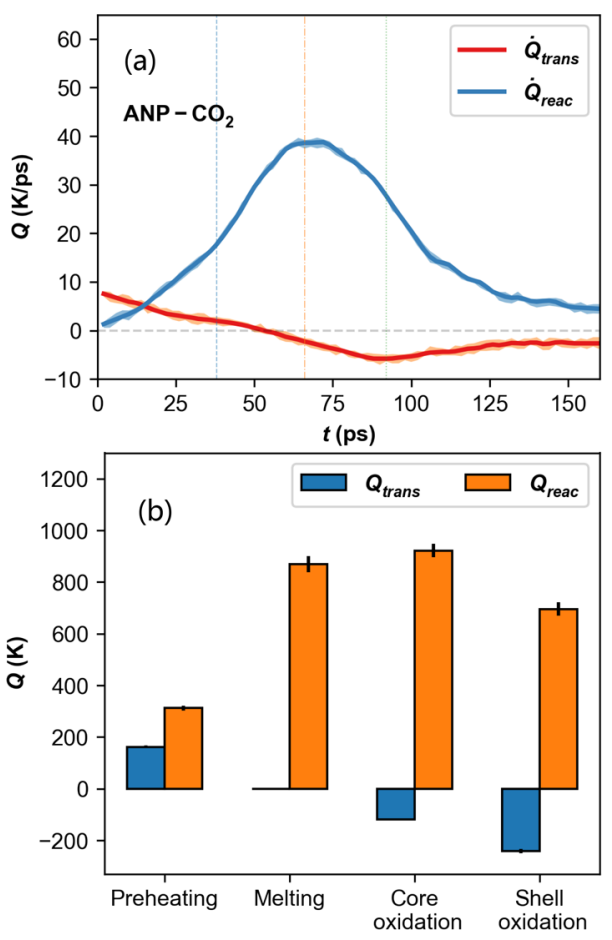

Figure 6. Variations of heat transfer and reaction heat release rates (a) and their integrals (b) in each stage.

color areas are the averaged values of three samples and the error bands, respectively. $\dot{Q}_{\text {trans }}$ initially decreases until a negative value, indicating that the contribution of input energy by heat transfer shrinks gradually or even inversely. Unlikely, $\dot{Q}_{\text {reac }}$ rises to the peak near the ignition owing to remarkable enhancement of chemisorption and reactive diffusion (see Figure 3a), and it drops thereafter. The contributions of the two heat sources in each stage are accumulated as shown in Figure $6 \mathrm{~b}$ in which error bars are added by short vertical lines. It can be seen that the low-temperature reaction in terms of chemisorption takes place before ANP ignition, and such reaction heat release plays a more significant role.

In the conventional ANP combustion theory, the heating of the particle is mainly attributed to conduction and radiation heat transfer. ${ }^{17}$ New evidence of the principal heat source is provided here to reveal the importance of the heterogeneous surface reaction before ignition. The contribution of the surface reaction is indispensable in the examination of ANP with a radius of tens of nanometers.

\section{DISCUSSION}

Changing the oxidizer from $\mathrm{CO}_{2}$ to $\mathrm{H}_{2} \mathrm{O}$ or $\mathrm{O}_{2}$ (denoted as ANP- $\mathrm{CO}_{2}, \mathrm{ANP}-\mathrm{H}_{2} \mathrm{O}$, and $\mathrm{ANP}-\mathrm{O}_{2}$, respectively), similar reaction processes were observed, indicating that ANP reaction modes are independent of the oxidizer type in the current study. However, the participation of three modes at each stage varies with respect to oxidizer properties, resulting in subsequently different ANP structures as well as heat release characteristics. The governing parameters on the reaction process should be identified, which are significant for effective control.

The variation of each mode during the reaction is summarized in Figure 7. Physisorption dominates in the preheating stage. As the reaction proceeds, the dominant mode evolves to chemisorption and reactive diffusion in that order. It should be pointed out that the reactive diffusion results from oxidizer atoms transferring toward the inner, which indicates the evolutions of the ANP microstructure. As illustrated in Figure 8 , in the case of $\mathrm{ANP}-\mathrm{CO}_{2}, \mathrm{C}$ atoms lie in the outermost shell with a small number density. As for ANP- $\mathrm{H}_{2} \mathrm{O}$, large amounts of $\mathrm{H}$ atoms diffuse into the inner zone of ANP. These behaviors are assumed to be correlated to diffusivity of specific oxidizer atoms. Here, the diffusivity $(D)$ of oxidizer atoms after ignition were calculated by the following equation $^{38}$

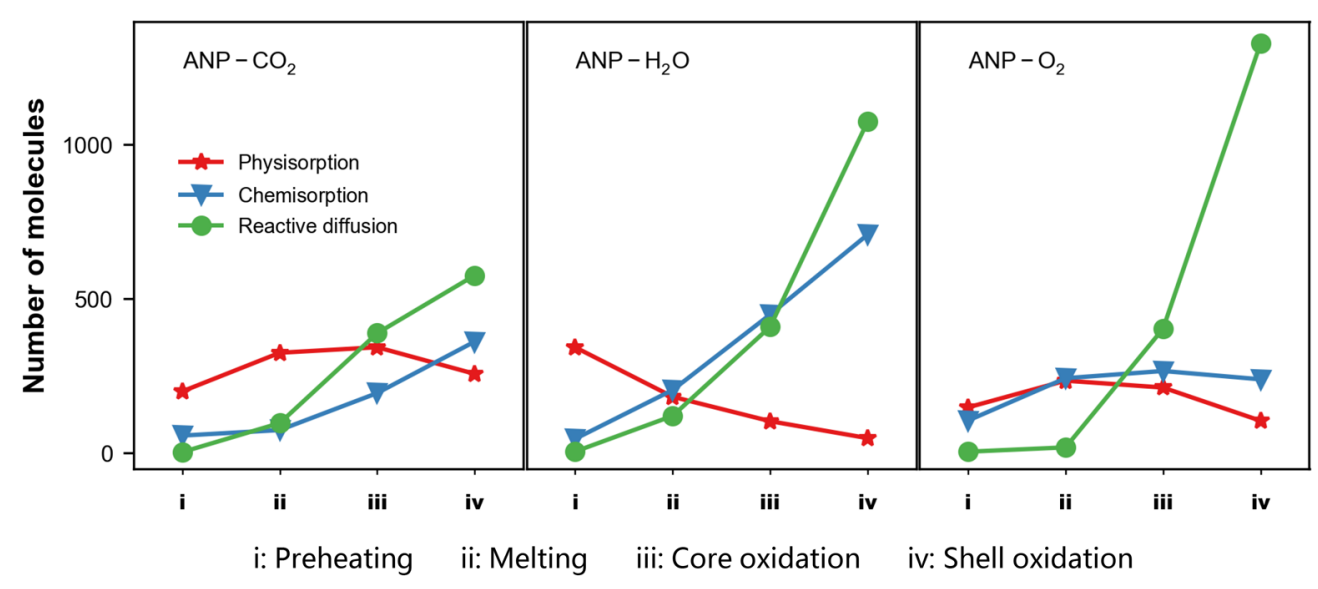

Figure 7. Numbers of adsorbed oxidizer molecules counted at the end of each stage indicating different reaction modes. 


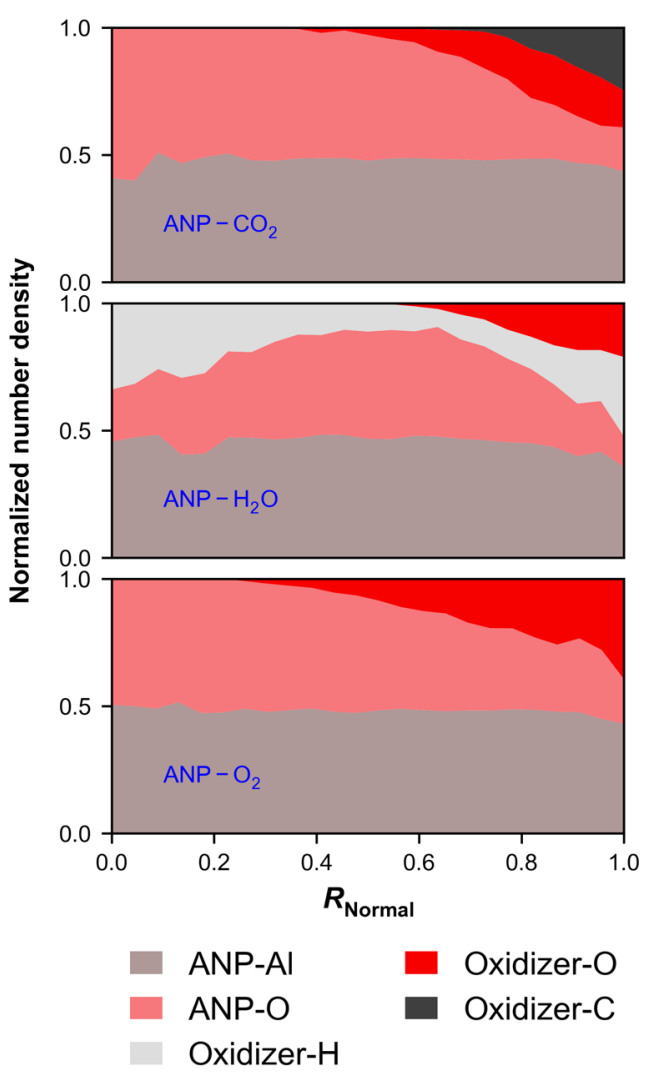

Figure 8. Radial distribution of normalized number density of ANP at the end of shell oxidation.

$$
D=\frac{1}{6 N} \lim _{t \rightarrow \infty} \frac{\mathrm{d}}{\mathrm{d} t} \sum_{i=1}^{N}\left(r_{i}(t)-r_{i}(0)\right)^{2}
$$

where $N$ is the number of atoms, $r_{i}(t)$ is the position of atom $i$ at the time instant $t$, and $r_{i}(0)$ is the initial position of atom $i$. The term $\left[r_{i}(t)-r_{i}(0)\right]$ represents the displacement of atom $i$ after a time interval of $t$. Each value is listed in Table 1 .

\section{Table 1. Atomic Diffusivity during Shell Oxidation}

\begin{tabular}{ccc} 
system & atom type & $D\left(\AA^{2} / \mathrm{ps}\right)$ \\
$\mathrm{ANP}-\mathrm{CO}_{2}$ & $\mathrm{O}$ from $\mathrm{CO}_{2}$ & 0.18376 \\
& $\mathrm{C}$ from $\mathrm{CO}_{2}$ & 0.10488 \\
$\mathrm{ANP}-\mathrm{H}_{2} \mathrm{O}$ & $\mathrm{H}$ from $\mathrm{H}_{2} \mathrm{O}$ & 1.94865 \\
& $\mathrm{O}$ from $\mathrm{H}_{2} \mathrm{O}$ & 0.04668 \\
$\mathrm{ANP}-\mathrm{O}_{2}$ & $\mathrm{O}$ from $\mathrm{O}_{2}$ & 0.25141 \\
\hline
\end{tabular}

The diffusivity of the $\mathrm{C}$ atom is lower than that of the $\mathrm{O}$ atom in the ANP- $\mathrm{CO}_{2}$ system, and that of the $\mathrm{H}$ atom is significantly higher in the ANP- $\mathrm{H}_{2} \mathrm{O}$ system, directly resulting in different intensities of reactive diffusion (as shown in Figures 7 and 8) through governing the atomic diffusion behaviors of oxidizer atoms. Similar diffusion features of $\mathrm{C}, \mathrm{H}$, and $\mathrm{O}$ atoms were also reported in a recent $\mathrm{RMD}$ simulation on ANP/ethanol combustion ${ }^{22}$ in which the $\mathrm{H}$ and $\mathrm{O}$ atoms diffuse into ANP more easily than the $\mathrm{C}$ atoms. These findings support that the diffusivity of the oxidizer atom is positively correlated to the reactive diffusion.

As indicated in Figure 7, in each stage, the proportion of dominant reaction mode varies with the oxidizer, which may lead to the differences in energy release. Hence, the characteristics of heat transfer and reaction heat release during an ANP reaction are investigated, as illustrated in Figure 9.

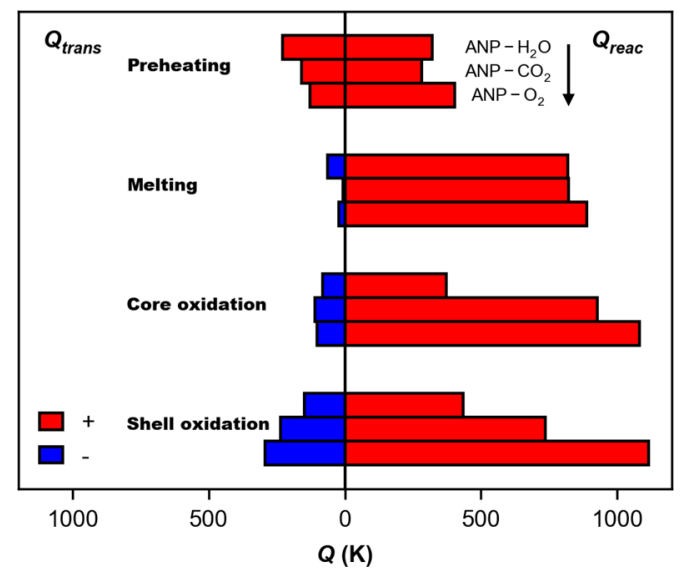

Figure 9. Heat transfer and reaction heat release in each stage in different oxidizers.

Heat transfer turns to negative from the melting stage, indicating heat transfer from ANP to the environment. In addition, $Q_{\text {reac }}$ is higher than $Q_{\text {tran }}$ throughout the four stages in the reaction, further indicating its significance as addressed in Section 3.3. As for the effect of oxidizers, $Q_{\text {reac }}$ varies slightly both in preheating and melting stages, while its value presents significant differences after ignition. The value of $Q_{\text {reac }}$ in ANP$\mathrm{H}_{2} \mathrm{O}$ shows a distinct decrease from the core oxidation stage in which reactive diffusion evolves to being dominant, probably attributed to the formation of $\mathrm{Al}-\mathrm{H}$ bonds after $\mathrm{H}$ atoms diffusing inside the ANP. Namely, the binding energies between $\mathrm{Al}$ and oxidizer atoms may significantly influence $Q_{\text {reac }}$.

At the ANP surface, $\mathrm{Al}$ atoms generally have higher binding energies with oxidizer atoms than those of $\mathrm{O}$ atoms. ${ }^{39}$ Hence, the $\mathrm{Al}$ atoms at the surface dominate the diffusion behaviors of oxidizer atoms. ${ }^{40}$ Accordingly, the binding energies of $\mathrm{Al}-\mathrm{C}$, $\mathrm{Al}-\mathrm{O}$, and $\mathrm{Al}-\mathrm{H}$ bonds are calculated by ReaxFF to be $168.21,131.23$, and $46.37 \mathrm{kcal} / \mathrm{mol}$, respectively, using a similar method mentioned in the literature. ${ }^{41}$ These values have a good agreement with those obtained by DFT and ReaxFF calculations. ${ }^{41,42}$ It is observed that the binding energy of the $\mathrm{Al}-\mathrm{H}$ bond is much lower than those of the other two ones, resulting in the lowest $Q_{\text {reac }}$ of $A N P-H_{2} \mathrm{O}$ during core and shell oxidation. However, even though with the highest binding energy in the $\mathrm{Al}-\mathrm{C}$ bond, the formation of $\mathrm{CO}$ molecules (as shown in Figure 3 described in Section 3.1) decreases the total number of $\mathrm{Al}-\mathrm{C}$ bonds. Owing to this secondary reaction in the case of ANP-CO $\mathrm{C}_{2}$ eac after ignition is lower than that in ANP- $\mathrm{O}_{2}$. In addition, a higher binding energy generally leads to a higher energy barrier for atomic diffusion, ${ }^{40}$ which may explain the high diffusivity of $\mathrm{H}$ atoms and the low values of $\mathrm{C}$ atoms in reactive diffusion.

It should be noted that the reactive diffusivity shown in Figure 7 is positively correlated to atomic diffusivity of the oxidizer but is inversely correlated to the binding energy with the $\mathrm{Al}$ atom. A high binding energy generally yields large $Q_{\text {reac }}$ but also a higher energy barrier to impede atomic diffusion.

As summarized in Figure 10, temperatures at melting point and core ignition are independent of the oxidizer. Since before core oxidation, the reactive diffusion is very weak (see Figure 


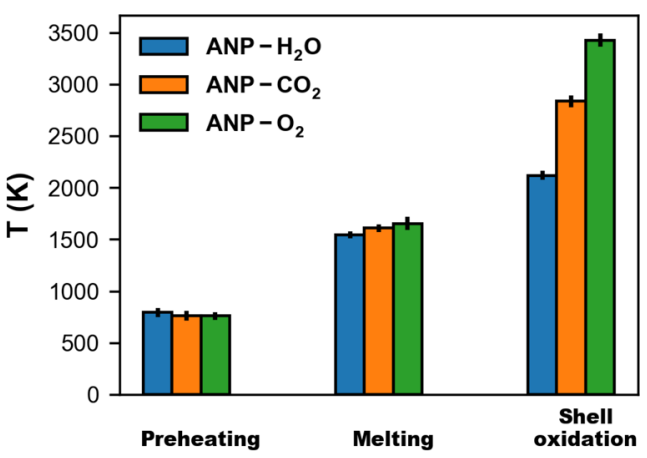

Figure 10. ANP average temperatures with error bars (short vertical lines) at the end of preheating, melting, and shell oxidation stages indicating the melting point, ignition, and final temperatures, respectively.

7), and the inner structure of ANP is rarely affected by the oxidizer (Figure 4 and Figure S2). The final temperature at the end of simulation increases as the oxidizer varies from $\mathrm{H}_{2} \mathrm{O}$ to $\mathrm{O}_{2}$ via $\mathrm{CO}_{2}$.

As one of the key factors in controlling, the ANP ignition delay time, that is, total durations of preheating and melting stages in this study (as shown in Figure 11), should be paid

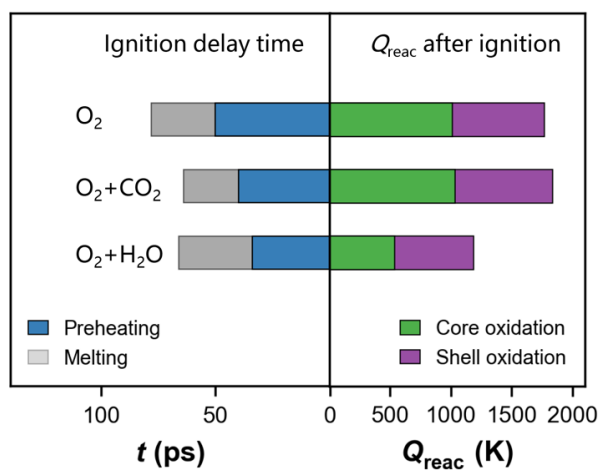

Figure 11. Ignition delay time indicated by overall durations of preheating and melting stages (left part) and reaction heat release after ignition (right part) in different oxidizers.

attention. In practice, it is ideal for fully utilizing the released heat during ANP burning in combustors or engines with a shorter ignition delay time and longer residence time. According to the fact that the preheating duration generally dominates the ignition delay time over melting, the preheating should be primarily accelerated.

Based on Figures 7 and 9, the oxidizer with strong physisorption will shorten the preheating duration. This point can be supported by Figure 11 and Figure S3. The pure $\mathrm{O}_{2}$ atmosphere yields a longer duration in the preheating stage owing to the relatively weaker physisorption (as shown in Figure 7). By replacing half of the $\mathrm{O}_{2}$ molecules by $\mathrm{CO}_{2}$ with stronger physisorption, the heat transfer is enhanced by the newly added $\mathrm{CO}_{2}\left(\mathrm{ANP}-\mathrm{O}_{2}+\mathrm{CO}_{2}\right)$, which shortens the preheating duration, clearly reducing the ignition delay time. By adopting $\mathrm{H}_{2} \mathrm{O}$ as the substitute $\left(\mathrm{ANP}-\mathrm{O}_{2}+\mathrm{H}_{2} \mathrm{O}\right)$, the preheating duration further decreases owing to the strongest physisorption of $\mathrm{H}_{2} \mathrm{O}$. On the other hand, we pursue high heat release ultimately, which is governed by core and shell oxidation (see Figure 9). $Q_{\text {reac }}$ after ignition indicates that $\mathrm{O}_{2}$ or a mixed oxidizer of $\mathrm{O}_{2}$ and $\mathrm{CO}_{2}$ (with high binding energy) should be adopted to yield more reaction heat.

Adopting $\mathrm{H}_{2} \mathrm{O}$ or $\mathrm{CO}_{2}$ in the early stage can shorten the ignition delay time. After ignition, employing the oxidizer with higher Al-binding energy may improve the heat release. By identifying the dominant reaction mode and corresponding heat transfer as well as reaction heat release characteristics in each stage, this study provides a guideline to manipulate the ANP reaction effectively.

\section{CONCLUSIONS}

The mechanism of the core-shell ANP reaction in a hot gaseous oxidizer (typically $\mathrm{CO}_{2}, \mathrm{H}_{2} \mathrm{O}$, and $\mathrm{O}_{2}$ ) was identified by examining the physical and chemical interactions between ANP and oxidizer molecules, evolution of the ANP microstructure, and heat and mass transfer processes. Three modes including physical as well as chemical adsorption at the surface and subsequent reactive diffusion inside the ANP were captured and categorized by the reaction routine. The results illustrate that physisorption dominates the reaction in the preheating stage. Gradually, the dominant mode evolves to chemisorption and reactive diffusion in that order from melting to shell oxidation stages. It is found that the reactive diffusivity is positively correlated to diffusivity of the oxidizer atom but is inversely correlated to the binding energy with $\mathrm{Al}$. In addition, the binding energy is positively correlated with reaction heat release, and it presents an inverse relation to atomic diffusivity, resulting in various ANP structures in different oxidizers.

Reaction heat release plays a dominant role in prompting ignition of ANP at the scale discussed in the current study. The ANP temperatures at core melting and ignition are independent of oxidizer properties; however, the durations for preheating and melting stages vary with the oxidizer.

This study focuses on the physicochemical reaction process between ANP and oxidizer molecules along with the heat and mass transfer characteristics, which may prove to be highly useful for a variety of applications. The key parameters on ANP ignition and heat release rate, as well as evolution of the ANP microstructure, are derived. It provides an available guide to direct manipulation of the ANP reaction process by, for example, adjusting the oxidizer components, prompting ANP ignition, and improving the heat release rate. Furthermore, the present simulation and characterization methods can be extended to the case of metal nanoparticle reactions with oxidizers and hydrocarbons/alcohols, which consist of $\mathrm{C}, \mathrm{H}, \mathrm{O}$, and even other elements.

\section{ASSOCIATED CONTENT}

\section{SI Supporting Information}

The Supporting Information is available free of charge at https://pubs.acs.org/doi/10.1021/acs.jpcc.9b11410.

Sensitivity analysis of bin size in surface definition (Figure S1); ANP microstructures near ignition (Figure S2); ignition delay time and reaction heat release after ignition in single component oxidizer (Figure S3) (PDF)

\section{AUTHOR INFORMATION}

\section{Corresponding Authors}

Baolu Shi - School of Aerospace Engineering, Beijing Institute of

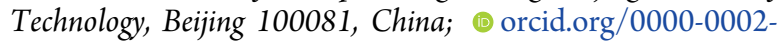


8638-4679; Phone: +86-10-6891-3623; Email: shibaolu@ bit.edu.cn, smashingsky@hotmail.com

Lijuan Liao - Key Laboratory for Mechanics in Fluid Solid Coupling Systems, Institute of Mechanics, Chinese Academy of Sciences, Beijing 100190, China; 이이.org/0000-00031753-6373; Phone: +86-10-8254-4291; Email: liaohuanxin@hotmail.com

\section{Authors \\ Qingzhao Chu - School of Aerospace Engineering, Beijing Institute of Technology, Beijing 100081, China \\ Xiangrui Zou - School of Aerospace Engineering, Beijing Institute of Technology, Beijing 100081, China \\ Kai H Luo - Department of Mechanical Engineering, University College London, London WC1E 7JE, United Kingdom; (1) orcid.org/0000-0003-4023-7259 \\ Ningfei Wang - School of Aerospace Engineering, Beijing Institute of Technology, Beijing 100081, China}

Complete contact information is available at: https://pubs.acs.org/10.1021/acs.jpcc.9b11410

\section{Notes}

The authors declare no competing financial interest.

\section{ACKNOWLEDGMENTS}

This work was supported by the Equipment Advance Research Field Foundation (Grant No. 61407200201) and National Natural Science Foundation of China (Grant Nos. 11672314 and 51676016). The computations were supported by the Computing Facility, Institute of Mechanics, Chinese Academy of Sciences, and Tianhe-2 National Supercomputer Center in Guangzhou. K.H.L.'s work was supported by the UK Engineering and Physical Sciences Research Council under the projects "UK Consortium on Mesoscale Engineering Sciences (UKCOMES)” (Grant Nos. EP/L00030X/1 and EP/ R029598/1).

\section{REFERENCES}

(1) Zhou, X.; Torabi, M.; Lu, J.; Shen, R.; Zhang, K. Nanostructured Energetic Composites: Synthesis, Ignition/Combustion Modeling, and Applications. ACS Appl. Mater. Interfaces 2014, 6, 3058-3074.

(2) Sippel, T. R.; Pourpoint, T. L.; Son, S. F. Combustion of Nanoaluminum and Water Propellants: Effect of Equivalence Ratio and Safety/Aging Characterization. Propellants, Explos., Pyrotech. 2013, 38, 56-66.

(3) Huang, H. T.; Zou, M. S.; Guo, X. Y.; Yang, R. J.; Li, Y. K. Analysis of the Aluminum Reaction Efficiency in a Hydro-Reactive Fuel Propellant Used for a Water Ramjet. Combust. Explos. Shock Waves 2013, 49, 541-547.

(4) Bergthorson, J. M. Recyclable Metal Fuels for Clean and Compact Zero-Carbon Power. Prog. Energy Combust. Sci. 2018, 68, 169-196.

(5) Mandilas, C.; Karagiannakis, G.; Konstandopoulos, A. G.; Beatrice, C.; Lazzaro, M.; Di Blasio, G.; Molina, S.; Pastor, J. V.; Gil, A. Study of Basic Oxidation and Combustion Characteristics of Aluminum Nanoparticles under Enginelike Conditions. Energy Fuels 2014, 28, 3430-3441.

(6) Bucher, P.; Yetter, R. A.; Dryer, F. L.; Vicenzi, E. P.; Parr, T. P.; Hanson-Parr, D. M. Condensed-Phase Species Distributions about Al Particles Reacting in Various Oxidizers. Combust. Flame 1999, 117, 351-361.

(7) Kwon, Y.-S.; Gromov, A. A.; Ilyin, A. P.; Popenko, E. M.; Rim, G.-H. The Mechanism of Combustion of Superfine Aluminum Powders. Combust. Flame 2003, 133, 385-391.
(8) Prentice, J. Combustion of Laser-Ignited Aluminum Droplets in Wet and Dry Oxidizers. In 12th Aerospace Sciences Meeting; American Institute of Aeronautics and Astronautics: Reston, Virigina, 1974; p 146.

(9) Roberts, T. A.; Burton, R. L.; Krier, H. Ignition and Combustion of Aluminummagnesium Alloy Particles in $\mathrm{O}_{2}$ at High Pressures. Combust. Flame 1993, 92, 125-143.

(10) Dreizin, E. L. On the Mechanism of Asymmetric Aluminum Particle Combustion. Combust. Flame 1999, 117, 841-850.

(11) Dreizin, E. L. Experimental Study of Aluminum Particle Flame Evolution in Normal and Micro-Gravity. Combust. Flame 1999, 116, 323-333.

(12) Brandstadt, K.; Frost, D. L.; Kozinski, J. A. Preignition Characteristics of Nano- And Micrometer-Scale Aluminum Particles in $\mathrm{Al}-\mathrm{CO}_{2}$ Oxidation Systems. Proc. Combust. Inst. 2009, 32, 19131919.

(13) Levitas, V. I.; Samani, K. Size and Mechanics Effects in SurfaceInduced Melting of Nanoparticles. Nat. Commun. 2011, 2, 284-286.

(14) Lynch, P.; Krier, H.; Glumac, N. A Correlation for Burn Time of Aluminum Particles in the Transition Regime. Proc. Combust. Inst. 2009, 32, 1887-1893.

(15) Bazyn, T.; Krier, H.; Glumac, N. Combustion of Nanoaluminum at Elevated Pressure and Temperature behind Reflected Shock Waves. Combust. Flame 2006, 145, 703-713.

(16) Glumac, N.; Krier, H.; Bazyn, T.; Eyer, R. Temperature Measurements of Aluminum Particles Burning in Carbon Dioxide. Combust. Sci. Technol. 2005, 177, 485-511.

(17) Sundaram, D. S.; Puri, P.; Yang, V. A General Theory of Ignition and Combustion of Nano- and Micron-Sized Aluminum Particles. Combust. Flame 2016, 169, 94-109.

(18) Wang, W.; Clark, R.; Nakano, A.; Kalia, R. K.; Vashishta, P. Fast Reaction Mechanism of a Core $(\mathrm{Al})$-Shell $\left(\mathrm{Al}_{2} \mathrm{O}_{3}\right)$ Nanoparticle in Oxygen. Appl. Phys. Lett. 2009, 95, 261901.

(19) Henz, B. J.; Hawa, T.; Zachariah, M. R. On the Role of Built-in Electric Fields on the Ignition of Oxide Coated Nanoaluminum: Ion Mobility versus Fickian Diffusion. J. Appl. Phys. 2010, 107, No. 024901.

(20) Douglas-Gallardo, O. A.; Soldano, G. J.; Mariscal, M. M.; Sánchez, C. G. Effects of Oxidation on the Plasmonic Properties of Aluminum Nanoclusters. Nanoscale 2017, 9, 17471-17480.

(21) Zeng, H.; Cheng, X.; Zhang, C.; Lu, Z. Responses of CoreShell $\mathrm{Al} / \mathrm{Al}_{2} \mathrm{O}_{3}$ Nanoparticles to Heating: ReaxFF Molecular Dynamics Simulations. J. Phys. Chem. C 2018, 122, 9191-9197.

(22) Zhang, Y. R.; van Duin, A. C. T.; Luo, K. H. Investigation of Ethanol Oxidation over Aluminum Nanoparticle Using ReaxFF Molecular Dynamics Simulation. Fuel 2018, 234, 94-100.

(23) Van Duin, A. C. T.; Dasgupta, S.; Lorant, F.; Goddard, W. A. ReaxFF: A Reactive Force Field for Hydrocarbons. J. Phys. Chem. A 2001, 105, 9396-9409.

(24) Spagnoli, D.; Gale, J. D. Atomistic Theory and Simulation of the Morphology and Structure of Ionic Nanoparticles. Nanoscale 2012, 4, 1051-1067.

(25) Chu, Q.; Shi, B.; Liao, L.; Luo, K. H.; Wang, N.; Huang, C. Ignition and Oxidation of Core-Shell $\mathrm{Al} / \mathrm{Al}_{2} \mathrm{O}_{3}$ Nanoparticles in an Oxygen Atmosphere: Insights from Molecular Dynamics Simulation. J. Phys. Chem. C 2018, 122, 29620-29627.

(26) Plimpton, S. Fast Parallel Algorithms for Short-Range Molecular Dynamics. J. Comput. Phys. 1995, 117, 1-19.

(27) Stukowski, A. Visualization and Analysis of Atomistic Simulation Data with OVITO-the Open Visualization Tool. Modell. Simul. Mater. Sci. Eng. 2010, 18, No. 015012.

(28) Hong, S.; Van Duin, A. C. T. Molecular Dynamics Simulations of the Oxidation of Aluminum Nanoparticles Using the ReaxFF Reactive Force Field. J. Phys. Chem. C 2015, 119, 17876-17886.

(29) Roussel, M.; Erdélyi, Z.; Schmitz, G. Reactive Diffusion and Stresses in Nanowires or Nanorods. Acta Mater. 2017, 131, 315-322.

(30) Paritskaya, L. N.; Bogdanov, V. V.; Kaganovskii, Y. SizeDependent Kinetics of Reactive Diffusion in Nano-Grained Ag-Sn Thin Films. Mater. Lett. 2017, 193, 292-294. 
(31) Tavoosi, M. The Kirkendall Void Formation in $\mathrm{Al} / \mathrm{Ti}$ Interface during Solid-State Reactive Diffusion between $\mathrm{Al}$ and Ti. Surfaces and Interfaces 2017, 9, 196-200.

(32) Nakamura, R.; Tokozakura, D.; Nakajima, H.; Lee, J.-G.; Mori, $\mathrm{H}$. Hollow Oxide Formation by Oxidation of $\mathrm{Al}$ and $\mathrm{Cu}$ Nanoparticles. J. Appl. Phys. 2007, 101, No. 074303.

(33) Aykol, M.; Persson, K. A. Oxidation Protection with Amorphous Surface Oxides: Thermodynamic Insights from Ab Initio Simulations on Aluminum. ACS Appl. Mater. Interfaces 2018, 10, 3039-3045.

(34) Wang, X.; Bu, C.; Zhang, J.; Chen, D.; Xie, H.; Piao, G. Adsorption of Lead, Cadmium , Sodium and Potassium Vapor Molecular on Met a-Kaolinite Surface : A DFT Study Modeling and Computational Details. In 12th Asia-Pacific Conference on Combustion; 2019; pp 1-5.

(35) Wang, Z.; Liu, J.; Zhang, B.; Yang, Y.; Zhang, Z.; Miao, S. Mechanism of Heterogeneous Mercury Oxidation by $\mathrm{HBr}$ over $\mathrm{V}_{2} \mathrm{O}_{5}$ / $\mathrm{TiO}_{2}$ Catalyst. Environ. Sci. Technol. 2016, 50, 5398-5404.

(36) Lu, X.; Jin, D.; Wei, S.; Zhang, M.; Zhu, Q.; Shi, X.; Deng, Z.; Guo, W.; Shen, W. Competitive Adsorption of a Binary $\mathrm{CO}_{2}-\mathrm{CH}_{4}$ Mixture in Nanoporous Carbons: Effects of Edge-Functionalization. Nanoscale 2015, 7, 1002-1012.

(37) Sensoy, M. G.; Ustunel, H.; Toffoli, D. First-Principles Investigation of $\mathrm{CO}$ and $\mathrm{CO}_{2}$ Adsorption on $\gamma-\mathrm{Al}_{2} \mathrm{O}_{3}$ Supported Monoatomic and Diatomic Pt Clusters. Appl. Surf. Sci. 2020, 499, 143968 .

(38) Desbrières, J.; Babak, V. G. Interfacial Properties of Amphiphilic Natural polymer systems based on derivatives of chitin. Polymer 2006, 55, 1177-1183.

(39) Wallin, E.; Andersson, J. M.; Münger, E. P.; Chirita, V.; Helmersson, U. Ab Initio Studies of $\mathrm{Al}, \mathrm{O}$, and $\mathrm{O}_{2}$ Adsorption on $\alpha$ $\mathrm{Al}_{2} \mathrm{O}_{3}$ (0001) Surfaces. Phys. Rev. B 2006, 74, 1-9.

(40) Nilekar, A. U.; Greeley, J.; Mavrikakis, M. A Simple Rule of Thumb for Diffusion on Transition-Metal Surfaces. Angew. Chem., Int. Ed. 2006, 45, 7046-7049.

(41) Hong, S.; Van Duin, A. C. T. Atomistic-Scale Analysis of Carbon Coating and Its Effect on the Oxidation of Aluminum Nanoparticles by ReaxFF-Molecular Dynamics Simulations. J. Phys. Chem. C 2016, 120, 9464-9474.

(42) Liu, P.; Liu, J.; Wang, M. Adsorption of Ethanol Molecules on the Al ( $\left.\begin{array}{lll}1 & 1 & 1\end{array}\right)$ Surface: A Molecular Dynamic Study. R. Soc. Open Sci. 2019, 6, 181189 . 